\title{
Amoebic liver abscess in a COVID-19 patient: a case report
}

\author{
Andrea L. Maricuto', Viledy L. Velásquez', Jacinto Pineda², David M. Flora-Noda'1, Isaac Rodríguez³, \\ Crismar A. Rodríguez-Inés ${ }^{4}$, Óscar O. Noya-González ${ }^{5}$, Rosa Contreras ${ }^{5}$, Óscar D. Omaña-Ávila,7, \\ Iván A. Escalante-Pérez ${ }^{6,7}$, Natasha A. Camejo-Ávila7, Nicolle A. Kuffaty-Akkou ${ }^{6,7}$, Fhabián S. Carrión-Nessi ${ }^{7,8}$, \\ Martín Carballo ${ }^{1}$, María E. Landaeta ${ }^{1}$ and David A. Forero-Peña ${ }^{1,7^{*}}$ (1)
}

\begin{abstract}
Background: Amoebiasis is a parasitic disease caused by Entamoeba histolytica, which affects people living in lowand middle-income countries and has intestinal and extraintestinal manifestations. To date, knowledge on coronavirus disease 2019 (COVID-19) coinfection with enteric parasites is limited, and E. histolytica coinfection has not been previously described. Here we present the case of a patient with COVID-19 who, during hospitalisation, presented a clinical picture consistent with an amoebic liver abscess (ALA).

Case presentation: A 54-year-old man, admitted as a suspected case of COVID-19, presented to our hospital with dyspnoea, malaise, fever and hypoxaemia. A nasopharyngeal swab was positive for severe acute respiratory syndrome coronavirus 2 (SARS-CoV-2) by reverse-transcription polymerase chain reaction. After 7 days, he developed diarrhoea, choluria and dysentery. An abdominal ultrasound showed a lesion compatible with a liver abscess; stool examination revealed E. histolytica trophozoites, and additional serology for E. histolytica was positive. After 12 days of treatment with metronidazole, ceftazidime and nitazoxanide, the patient reported acute abdominal pain, and an ultrasound examination revealed free liquid in the abdominal cavity. An emergency exploratory laparotomy was performed, finding $3000 \mathrm{~mL}$ of a thick fluid described as "anchovy paste". Computed tomography scan revealed a second abscess. He ended up receiving 21 days of antibiotic treatment and was discharged with satisfactory improvement.

Conclusion: Here we present, to the best of our knowledge, the first report of ALA and COVID-19 co-presenting. Based on their pathophysiological similarities, coinfection with SARS-CoV-2 and E. histolytica could change the patient's clinical course; however, larger studies are needed to fully understand the interaction between these pathogens.
\end{abstract}

Keywords: Amoebic liver abscess, Entamoeba histolytica, COVID-19, SARS-CoV-2, Venezuela, Case report

\section{Background}

Coronavirus disease 2019 (COVID-19), caused by severe acute respiratory syndrome coronavirus 2 (SARS-CoV-2), has become a public health problem worldwide [1]. The lung is considered the main organ affected by COVID-19;

\footnotetext{
*Correspondence: vacter.cv@gmail.com

1 Infectious Diseases Department, University Hospital of Caracas, Caracas, Venezuela

Full list of author information is available at the end of the article
}

however, extrapulmonary symptoms may also manifest during the disease. SARS-CoV-2 was detected in the stool of the first reported case of COVID-19 in the United States, which also presented digestive symptoms, prompting interest in the gastrointestinal manifestations of COVID-19 [2]. Gastrointestinal and hepatic presentations are not rare; diarrhoea and mild elevation of liver enzymes are the most common characteristics of COVID-19, in the absence of pre-existing diseases [3]. 
Recent studies on COVID-19 have shown a high incidence of liver injury ranging from 14.8 to $53 \%$, mainly indicated by abnormal alanine transaminase/aspartate transaminase levels accompanied by slightly elevated bilirubin levels. The proportion of patients who develop liver injury in severe COVID-19 seems to be higher than in mild cases [4-7]. SARS-CoV-2 uses angiotensin-converting enzyme 2 (ACE2) as its entry receptor [8], which is expressed in liver and bile duct cells $[9,10]$, suggesting direct liver injury in patients with COVID-19.

There is limited knowledge on the prevalence of coinfections among patients with COVID-19, especially in organs and systems other than the respiratory tract. Intestinal parasitic infections affect more than 2 billion people worldwide, with disproportionately high prevalence rates in low- and middle-income countries [11]. Amoebiasis is a parasitic disease caused by Entamoeba histolytica, and has intestinal and extraintestinal manifestations. Amoebic liver abscess (ALA) is the most common extraintestinal manifestation in any setting, including Venezuela [12]. Coinfection with SARS-CoV-2 could change the clinical course of the patient; however, this coinfection has not been previously described. Here we present the case of a patient with COVID-19 who, during hospitalisation, presented a clinical picture consistent with an ALA.

\section{Case presentation}

A 54-year-old man presented to the Infectious Diseases Department of the University Hospital of Caracas with dyspnoea, malaise and fever over 6 days; he was admitted as a suspected case of COVID-19 due to hypoxaemia (oxygen saturation $<90 \%$ ) with no significant medical history. On admission, blood test showed neutrophilia $\left(8.05 \times 10^{3} / \mu \mathrm{L}\right)$, lymphopenia $\left(0.88 \times 10^{3} /\right.$ $\mu \mathrm{L}$ ), mild transaminases elevation (aspartate aminotransferase: $40 \mathrm{U} / \mathrm{L}$; alanine aminotransferase: $69 \mathrm{U} / \mathrm{L}$ ), bilirubin levels within normal range (total bilirubin: $0.5 \mathrm{mg} / \mathrm{dL}$; indirect bilirubin: $0.3 \mathrm{mg} / \mathrm{dL}$; direct bilirubin: $0.2 \mathrm{mg} / \mathrm{dL}$ ), and inflammatory markers elevation (lactate dehydrogenase: $394 \mathrm{U} / \mathrm{L} ; \mathrm{C}$-reactive protein: $9.1 \mathrm{mg} / \mathrm{L}$; erythrocyte sedimentation rate: $55 \mathrm{~mm} / \mathrm{h}$ ). Human immunodeficiency virus serology was performed according to the Infectious Diseases Department protocol, with a non-reactive result. A nasopharyngeal swab was positive for SARS-CoV-2 by reverse-transcription polymerase chain reaction. After 7 days, he presented diarrhoea, choluria and then dysentery; subsequent liver function tests revealed transaminases limit values (aspartate aminotransferase: $31.6 \mathrm{U} / \mathrm{L}$; alanine aminotransferase: $45.8 \mathrm{U} / \mathrm{L}$ ), and mild indirect bilirubin elevation (total bilirubin: $1.16 \mathrm{mg} / \mathrm{dL}$; indirect bilirubin: $0.74 \mathrm{mg} / \mathrm{dL}$; direct bilirubin: $0.42 \mathrm{mg} / \mathrm{dL}$ ). An abdominal ultrasound showed an image compatible with an ALA; stool examination revealed E. histolytica trophozoites. Serological diagnosis was performed by enzyme-linked immunosorbent assay, obtaining an optical density of 0.325 (our institution's cut-off point using healthy patient sera was 0.215). Immediately, treatment with metronidazole, ceftazidime and nitazoxanide was started. Although the patient presented clinical improvement, on day 12 of treatment the patient reported acute abdominal pain, and an ultrasound examination revealed free liquid in the abdominal cavity. An emergency exploratory laparotomy was performed, finding $3000 \mathrm{~mL}$ of a thick fluid described as "anchovy paste". Liver biopsy showed hepatocytes with ballooning degeneration (Fig. 1A), acidophilic bodies (Fig. 1B), binucleated and trinucleated hepatocytes (Fig. 1C, D), glycogenic intranuclear vacuolisation (Fig. 1E), moderate microvesicular steatosis (Fig. 1F), necrotic hepatocytes around the central vein (Fig. 1G), moderate inflammation in the portal tracts with occasional lymphocytic infiltrate (Fig. $1 \mathrm{H}$ ), large fibrin thrombus in the portal vein branch (Fig. 1I), and ductular and intracanalicular cholestasis (Fig. 1J, K). Furthermore, Kupffer cells were hypertrophic (Fig. 1L); there was no interphase hepatitis. Computed tomography scan revealed a second abscess (Fig. 2A), which was drained by percutaneous drainage (Fig. 2B). The patient ended up receiving 21 days of antibiotic treatment and was discharged with satisfactory improvement.

\section{Discussion and conclusions}

Gastrointestinal symptoms are common in patients with COVID-19, but the prevalence of coinfection with enteric pathogens is unknown. Recently, a retrospective study concluded that patients with COVID-19 were less likely to test positive for coinfection with typical gastrointestinal pathogens (except with Clostridium difficile) compared to those without COVID-19 [13]. In Venezuela, the prevalence of $E$. histolytica/E. dispar infection varies from one region to another (6.8-42\%), mainly affecting school-age children from Zulia, Falcón, Táchira, Lara, Aragua and Sucre states [12, 14]; however, the epidemiology of this parasitosis in the Capital District (Caracas) is unknown. Here we present the case of a patient with confirmed COVID-19 who, during hospitalisation, presented a clinical picture consistent with an ALA, identifying $E$. histolytica as the aetiological agent through a stool examination, and, secondly, by the frank seropositivity of an "in-house" ELISA; furthermore, the evidence of a typical image in the liver parenchyma with liquid collection, negative for bacterial infection, 

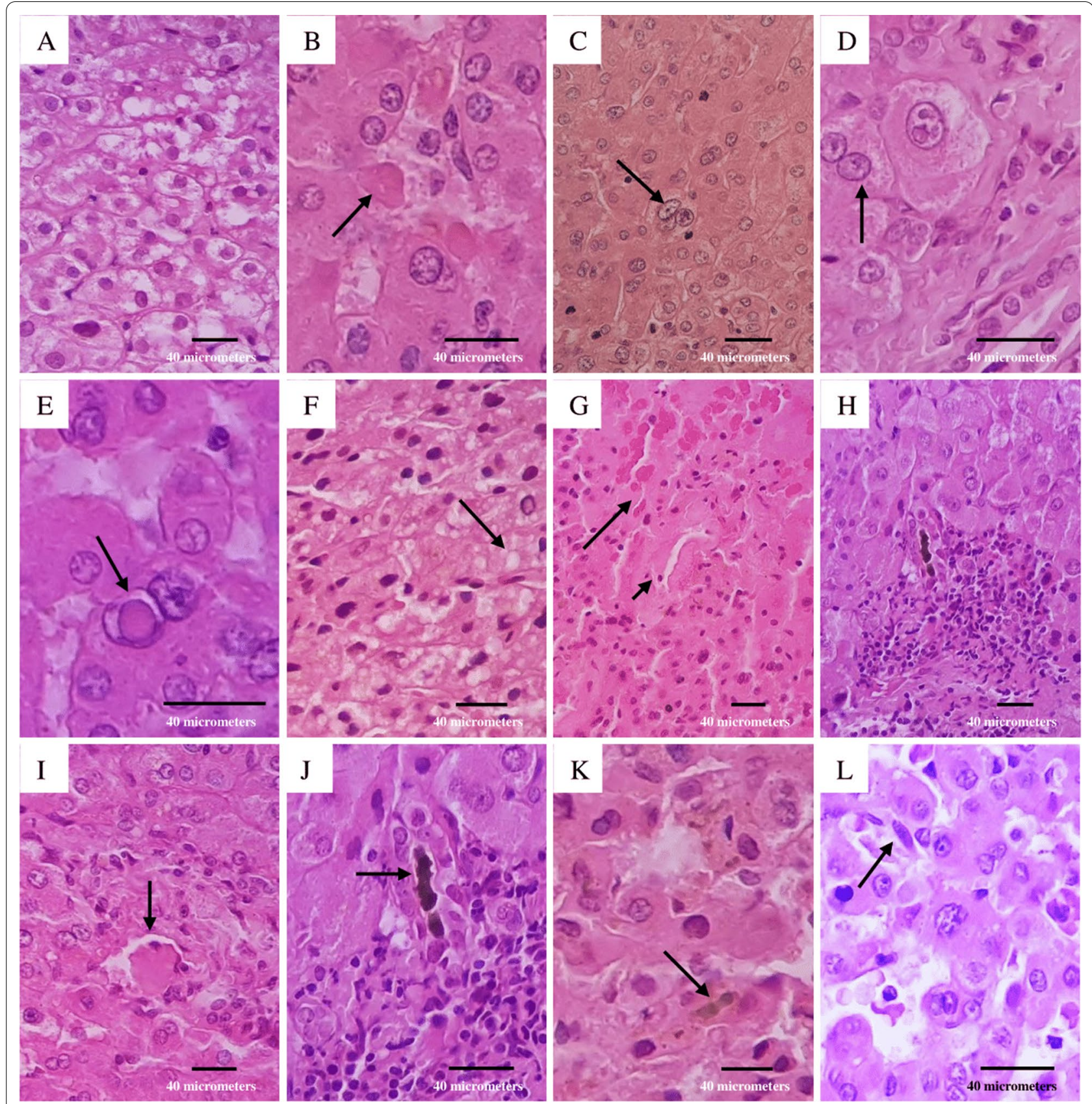

Fig. 1 Liver biopsy. A Swelling of hepatocytes with increased and pale cytoplasm; B eosinophilic round body (arrow); C binucleated hepatocytes (arrow); $\mathbf{D}$ trinucleated hepatocytes (arrow); $\mathbf{E}$ homogeneous clearing of hepatocyte nuclei (arrow); $\mathbf{F}$ multiple tiny intracytoplasmic fat droplets that do not displace the nucleus (arrow); $\mathbf{G}$ necrotic hepatocytes (big arrow) around the central vein (small arrow); $\mathbf{H}$ inflammatory infiltrate composed by lymphocytes; I large fibrin thrombus in portal vein branch (arrow); J bile plug in the bile duct (arrow); $\mathbf{K}$ bile plug in the bile canaliculi (arrow); L Kupffer cells proliferate and enlarge in response to hepatocyte damage (arrow). The microscope used was a Leica DM500 (Leica Microsystems Inc., IL, United States) and the image was captured with a Samsung Galaxy M20 smartphone (Samsung Electronics, Seoul, South Korea). Images were acquired at a resolution of 20 megapixels and edited with the phone's own software, then processed using Microsoft ${ }^{\circledR}$ Exce $^{\circledR}$ version 2019 (Microsoft, WA, United States)

supported this idea. However, in this case it was not possible to identify amoebic trophozoites and cysts, probably due to the location of the sample taken, as the parasites are predominantly located around the healthy margins of liver abscesses, where they feed on cytolytised hepatocytes [15]. 

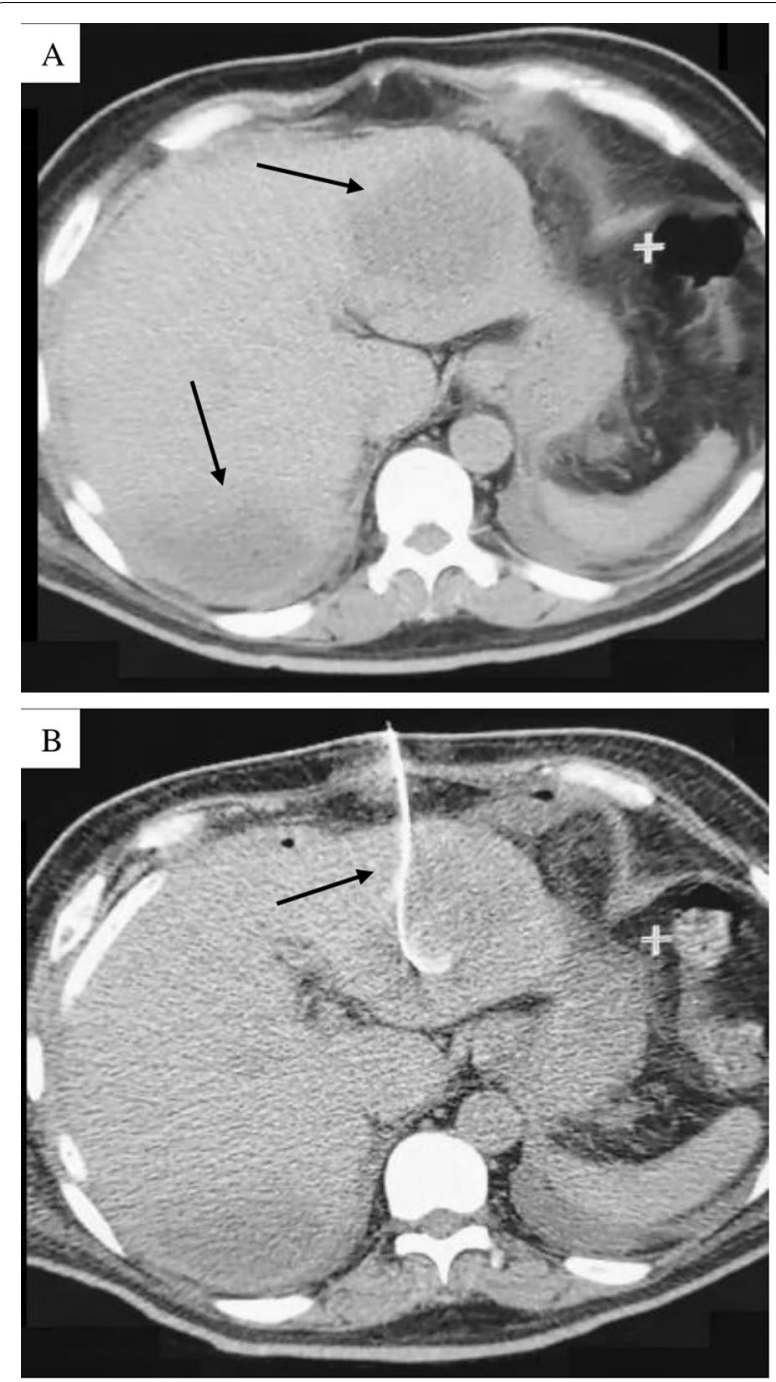

Fig. 2 Computed tomography. A Axial section of abdominal computed tomography scan without contrast administration showing an enlarged liver (caudal skull diameter: $18 \mathrm{~cm}$ ), at least two images were located in segments II and VIII of rounded morphology, regular edges, hypodense (Hounsfield Units: 20), the largest with 150 cc volume, likely related to liver abscess; $\mathbf{B}$ axial section of abdominal computed tomography scan without oral or intravenous contrast administration, showing the placement of a catheter for drainage of the liver abscess located in segment II
This case occurred simultaneously with the identification of an in-hospital amoebiasis flare-up caused by hospital kitchen staff infected by this parasite, where 37 persons directly involved in food preparation were evaluated and intestinal amoebiasis was documented in four of them (10.8\%) (unpublished data). Considering the faecal-oral transmission of this parasitosis and its incubation time, the patient could acquire the disease by consuming contaminated water or food before admission to the hospital.

Entamoeba histolytica infection can be asymptomatic or symptomatic, and can lead to tissue invasion. The most common invasive extraintestinal manifestation is ALA: the parasite reaches the liver via the portal circulation. Usually, in this presentation, there is no evidence of previous colitis, suggesting an asymptomatic infection or confined to the right side of the colon [16]. Persistence, establishment and consequent clinical presentations of infection depend on the pathological characteristics of the protozoan, but it is also affected by the host immune response. ALA occurs in a minority of patients with amoebiasis (3-9\%) [16], and complications such as abscess rupture $(2.5-22 \%)[17,18]$ and peritonitis (2.4-13\%) may develop, associated with higher mortality $(40-50 \%)[17,19]$. ALA diagnosis is performed by clinical history, ultrasound (sensitivity varies as it is an operator-dependent study) [20, 21] or computed tomography scan (higher sensitivity than ultrasound) [22] in combination with a confirmatory laboratory study, such as enzyme-linked immunosorbent assay due to its high sensitivity and specificity [23]. In endemic areas, the use of serological tests based on E. histolytica recombinant antigens is preferable, if available, as it only detects active infections [24]. Although $70-80 \%$ of ALA cases have only one abscess mainly located in the right lobe of the liver [25], there seems to be an increase of the incidence of multiple ALA due to the improved imaging studies [26]. Coinfection with ALA and gram-negative bacteria, mainly Klebsiella pneumoniae and Escherichia coli, is commonly found among cases of multiple abscesses $[26,27]$, although cases of simultaneous infection with hepatotropic virus are anecdotal [28].

ACE2 receptors have been identified in the gastrointestinal tract and liver, which are highly expressed in the endothelial layer of small blood vessels, but not in the sinusoidal endothelium. Recent studies have also found higher ACE2 receptor expression in cholangiocytes than in hepatocytes; in fact, ACE2 levels in cholangiocytes are similar to those in lung type- 2 alveolar cells, suggesting that the liver may be a potential target of SARS-CoV-2 [29]. Moreover, elevated prostaglandin E2 (PGE2) levels have been associated with ALA formation due to an immunosuppressive effect of PGE2 [30]. We can hypothesise that, in our patient, elevated PGE2 levels are secondary to both direct stimulation of cyclooxygenase-2 (COX-2) by SARS-CoV2-2 [31] and presence of a COX2-like protein present in E. histolytica trophozoites [30], which could influence the clinical course; however, the available knowledge is still insufficient to correlate them with each other. 
In this case, the patient required an exploratory laparotomy which showed secondary peritonitis due to ALA rupture. There is no consensus on the optimal treatment of complicated ALA with diffuse peritonitis; however, percutaneous drainage appears to be the preferred standard treatment in complicated ALA, and evidence suggests that drainage plus antimicrobial therapy (amoebicidal agent) has an excellent outcome [19]. In this case, despite empirical antimicrobial therapy, the patient required an exploratory laparotomy which showed secondary peritonitis due to rupture of the ALA. Combination antimicrobial therapy was maintained as the patient's condition deteriorated and toxaemia impressed prior to surgery. In addition, adequate samples were not taken before starting empirical antibiotic treatment. Histology showed hepatocytes with ballooning degeneration and acidophilic bodies, consistent with another study [32]. Binuclear and multinuclear hepatocytes were identified, similar to the findings of Wang et al. [33], who report that this morphological phenomenon may be attributed to reactive changes. Few hepatocytes showed glycogenic intranuclear vacuolisation, a finding that contrasts with that found by Pessolani et al. [34], who described many hepatocytes with this finding. In a series of 40 cases, Lagana et al. [35] found macrovesicular steatosis in all patients, whereas microvesicular steatosis was found in our patient. It is well known that drugs, infections, malnutrition and various other insults cause fatty liver [35].

Necrotic hepatocytes and portal inflammation were consistent in the literature consulted. Schmit et al. [36] observed necrosis in zone III in most cases, similar to that found in our patient. Thrombotic phenomenon was observed in our case. The mechanism of this prothrombotic milieu remains to be determined; however, this morphological finding suggest a profound platelet response in COVID-19 that may be responsible, at least in part, for multiple organ dysfunction [37]. An investigation by Diaz et al. [38] showed that this phenomenon may be due to an endothelial dysfunction, a procoagulant state and/or a direct vascular injury of the disease. Ductular and bile canaliculus cholestasis suggest sepsis and functional cholangiocytes injure [35], respectively, a morphological manifestation observed in our patient. Another morphological phenomenon observed was Kupffer cells hypertrophy and hyperplasia, findings similar to those reported by Diaz et al. [38]; however, the pathophysiological mechanism of this morphological manifestation is still unknown.

Although gastrointestinal and liver involvement by SARS-CoV-2 has been described, there is no demonstration that COVID-19 may predispose to other gastrointestinal involvement. Conversely, a recent study found that coinfection with parasitic diseases appears to be associated with reduced severity by COVID-19, suggesting that parasite-driven immunomodulatory responses may mute the hyperinflammation associated with severe COVID-19 [39]. To our knowledge, this is the first report of simultaneous presentation of ALA and COVID-19. In our case, it is likely that there is no causal relationship; however, the likelihood of coinfection is highlighted in regions with a high incidence of intestinal amoebiasis, which should be diagnosed and treated early. Based on their pathophysiological similarities, coinfection with SARS-CoV-2 and E. histolytica could change the patient's clinical course; however, larger studies are needed to fully understand the interaction between these pathogens.

\section{Abbreviations}

COVID-19: Coronavirus disease 2019; SARS-CoV-2: Severe acute respiratory syndrome coronavirus 2; ACE2: Angiotensin-converting enzyme 2; ALA: Amoebic liver abscess; PGE2: Prostaglandin E2; COX-2: Cyclooxygenase-2.

\section{Acknowledgements}

We thank all staff of the Infectious Diseases Department of the University Hospital of Caracas and the research staff involved in the work.

\section{Authors' contributions}

$A M, V V, J P, O O-A$, IE-P, NC-A, NK-A, and DF-P carried out the literature search and drafted the first version of the manuscript. AM, DF-N, ON-G, RC were responsible for designing. IR, CR-I, FC-N, MC, ML, and DF-P supervised the completion of this case report and substantively revised it. All authors read and approved the final manuscript.

\section{Funding}

The authors received no specific funding for this work.

Availability of data and materials

All data and materials in this article are included in the manuscript.

\section{Declarations}

Ethics approval and consent to participate Not applicable.

\section{Consent for publication}

We have obtained the patient's written consent for the publication of his personal and clinical data and for the publication of the images illustrated in Figs. 1 and 2.

\section{Competing interests}

The authors declare no competing interests.

\section{Author details}

${ }^{1}$ Infectious Diseases Department, University Hospital of Caracas, Caracas, Venezuela. ${ }^{2 " D r}$. José Antonio O'Daly" Anatomopathological Institute, Central University of Venezuela, Caracas, Venezuela. ${ }^{3}$ Radiodiagnosis Department, University Hospital of Caracas, Caracas, Venezuela. ${ }^{4}$ Surgery Department, University Hospital of Caracas, Caracas, Venezuela. "Dr. Félix Pifano"Tropical Medicine Institute, Central University of Venezuela, Caracas, Venezuela. 6"Luis Razetti" School of Medicine, Central University of Venezuela, Caracas, Venezuela. ${ }^{7}$ Biomedical Research and Therapeutic Vaccines Institute, Ciudad Bolivar, Venezuela. "Dr. Francisco Battistini Casalta" Health Sciences School, University of Oriente - Bolivar Nucleus, Ciudad Bolivar, Venezuela. 
Received: 27 July 2021 Accepted: 26 October 2021

Published online: 04 November 2021

\section{References}

1. Coronavirus disease (COVID-19) pandemic. https://www.who.int/emerg encies/diseases/novel-coronavirus-2019.

2. Holshue ML, DeBolt C, Lindquist S, Lofy KH, Wiesman J, Bruce H, Spitters C, Ericson K, Wilkerson S, Tural A, et al. First case of 2019 novel coronavirus in the United States. N Engl J Med. 2020;382(10):929-36.

3. Zarifian A, Zamiri Bidary M, Arekhi S, Rafiee M, Gholamalizadeh H, Amiriani A, Ghaderi MS, Khadem-Rezaiyan M, Amini M, Ganji A. Gastrointestinal and hepatic abnormalities in patients with confirmed COVID-19: a systematic review and meta-analysis. J Med Virol. 2021;93(1):336-50.

4. Huang C, Wang Y, Li X, Ren L, Zhao J, Hu Y, Zhang L, Fan G, Xu J, Gu X, et al. Clinical features of patients infected with 2019 novel coronavirus in Wuhan, China. Lancet. 2020;395(10223):497-506.

5. Zhang B, Zhou X, Qiu Y, Song Y, Feng F, Feng J, Song Q, Jia Q, Wang J. Clinical characteristics of 82 cases of death from COVID-19. PLoS ONE. 2020;15(7):e0235458.

6. Xu L, Liu J, Lu M, Yang D, Zheng X. Liver injury during highly pathogenic human coronavirus infections. Liver Int. 2020;40(5):998-1004.

7. Zhang Y, Zheng L, Liu L, Zhao M, Xiao J, Zhao Q. Liver impairment in COVID-19 patients: a retrospective analysis of 115 cases from a single centre in Wuhan city, China. Liver Int. 2020;40(9):2095-103.

8. Hoffmann M, Kleine-Weber H, Schroeder S, Krüger N, Herrler T, Erichsen S, Schiergens TS, Herrler G, Wu NH, Nitsche A, et al. SARS-CoV-2 cell entry depends on ACE2 and TMPRSS2 and is blocked by a clinically proven protease inhibitor. Cell. 2020;181(2):271-280.e278.

9. Chai X, Hu L, Zhang Y, Han W, Lu Z, Ke A, Zhou J, Shi G, Fang N, Fan J, et al. Specific ACE2 expression in cholangiocytes may cause liver damage after 2019-nCoV infection. bioRxiv; 2020.

10. Pirola CJ, Sookoian S. SARS-CoV-2 virus and liver expression of host receptors: putative mechanisms of liver involvement in COVID-19. Liver Int. 2020;40(8):2038-40

11. Herricks JR, Hotez PJ, Wanga V, Coffeng LE, Haagsma JA, Basáñez MG, Buckle G, Budke CM, Carabin H, Fèvre EM, et al. The global burden of disease study 2013: what does it mean for the NTDs? PLoS Negl Trop Dis. 2017;11(8):e0005424.

12. Rivero Z, Bracho Á, Calchi M, Díaz I, Acurero E, Maldonado A, Chourio G, Arráiz N, Corzo G. Detección y diferenciación de Entamoeba histolytica y Entamoeba dispar mediante reacción en cadena de la polimerasa en individuos de una comunidad del Estado Zulia, Venezuela. Cad Saude Publica. 2009;25(1):151-9.

13. Laszkowska M, Kim J, Faye AS, Joelson AM, Ingram M, Truong H, Silver ER, May B, Greendyke WG, Zucker J, et al. Prevalence of clostridioides difficile and other gastrointestinal pathogens in patients with COVID-19. Dig Dis Sci. 2021; https://doi.org/10.1007/s10620-020-06760-y.

14. Bracho Mora Á. Entamoeba histolytica y Entamoeba dispar en Venezuela, desde el año 2003 a la actualidad: Una revisión. Saber. 2015;27(1):17-24.

15. Bhambhani S, Kashyap V. Amoebiasis: diagnosis by aspiration and exfoliative cytology. Cytopathology. 2001;12(5):329-33.

16. Irusen EM, Jackson TF, Simjee AE. Asymptomatic intestinal colonization by pathogenic Entamoeba histolytica in amebic liver abscess: prevalence, response to therapy, and pathogenic potential. Clin Infect Dis. 1992;14(4):889-93.

17. Meng XY, Wu JX. Perforated amebic liver abscess: clinical analysis of 110 cases. South Med J. 1994:87(10):985-90.

18. Quezada-Adame I, Medina-Villaseñor EA, del Carmen F-G, Cabrera-Albarrán A, Balice-Olguín O, Avilés-Tlalpan MP. Peritonitis amibiana por ruptura de absceso hepático. Cir Gen. 2007:29(1):17-21.

19. Kumar R, Anand U, Priyadarshi RN, Mohan S, Parasar K. Management of amoebic peritonitis due to ruptured amoebic liver abscess: it's time for a paradigm shift. JGH Open. 2019;3(3):268-9.

20. Kimura K, Stoopen M, Reeder MM, Moncada R. Amebiasis: modern diagnostic imaging with pathological and clinical correlation. Semin Roentgenol. 1997;32(4):250-75.
21. Elzi L, Laifer G, Sendi P, Ledermann HP, Fluckiger U, Bassetti S. Low sensitivity of ultrasonography for the early diagnosis of amebic liver abscess. Am J Med. 2004;117(7):519-22.

22. Mortelé KJ, Segatto E, Ros PR. The infected liver: radiologic-pathologic correlation. Radiographics. 2004;24(4):937-55.

23. Fotedar R, Stark D, Beebe N, Marriott D, Ellis J, Harkness J. Laboratory diagnostic techniques for Entamoeba species. Clin Microbiol Rev. 2007;20(3):511-32 (table of contents).

24. Stanley SL Jr, Jackson TF, Foster L, Singh S. Longitudinal study of the antibody response to recombinant Entamoeba histolytica antigens in patients with amebic liver abscess. Am J Trop Med Hyg. 1998;58(4):414-6.

25. Nattakom S, Serrato P, Bright T, Anaya A, Stubbers S, Verghese A. Amebic liver abscesses masquerading as pyemic abscesses. Clin Infect Dis. 2001;33(12):E145-147.

26. Chakrabarti S. Multiple amoebic liver abscess as initial manifestation in HIV sero-positive male. J Clin Diagn Res. 2015;9(6):Od04-5.

27. Tayal A, Lal P, Uppal B. Single and multiple liver abscesses in adults in Delhi are amoebic in origin: a clinical and microbiological study. Trop Dr. 2013;43(2):77-9.

28. Schwartz E, Piper-Jenks N. Simultaneous amoebic liver abscess and hepatitis A infection. J Travel Med. 1998;5(2):95-6.

29. Jothimani D, Venugopal R, Abedin MF, Kaliamoorthy I, Rela M. COVID-19 and the liver. J Hepatol. 2020;73(5):1231-40.

30. Dey I, Keller K, Belley A, Chadee K. Identification and characterization of a cyclooxygenase-like enzyme from Entamoeba histolytica. Proc Natl Acad Sci USA. 2003;100(23):13561-6.

31. Chen JS, Alfajaro MM, Wei J, Chow RD, Filler RB, Eisenbarth SC, Wilen CB. Cyclooxgenase-2 is induced by SARS-CoV-2 infection but does not affect viral entry or replication. bioRxiv. 2020

32. Chau TN, Lee KC, Yao H, Tsang TY, Chow TC, Yeung YC, Choi KW, Tso YK, Lau T, Lai ST, et al. SARS-associated viral hepatitis caused by a novel coronavirus: report of three cases. Hepatology. 2004;39(2):302-10.

33. Wang Y, Liu S, Liu H, Li W, Lin F, Jiang L, Li X, Xu P, Zhang L, Zhao L, et al. SARS-COV-2 infection of the liver directly contributes to hepatic impairment in patients with COVID-19. J Hepatol. 2020;73(4):807-16.

34. González Pessolani T, Muñóz Fernández de Legaria M, Elices Apellániz M, Salinas Moreno S, Lorido Cortés MdM, García Sánchez S. Multi-organ pathological findings associated with COVID-19 in postmortem needle core biopsies in four patients and a review of the current literature. Rev Esp Patol. 2020. https://doi.org/10.1016/j.patol.2020.09.003.

35. Lagana SM, Kudose S, luga AC, Lee MJ, Fazlollahi L, Remotti HE, Del Portillo A, De Michele S, de Gonzalez AK, Saqi A, et al. Hepatic pathology in patients dying of COVID-19: a series of 40 cases including clinical, histologic, and virologic data. Mod Pathol. 2020;33(11):2147-55.

36. Schmit G, Lelotte J, Vanhaebost J, Horsmans Y, Van Bockstal M, Baldin P. The liver in COVID-19-related death: protagonist or innocent bystander? Pathobiology. 2021;88(1):88-94

37. Rapkiewicz AV, Mai X, Carsons SE, Pittaluga S, Kleiner DE, Berger JS, Thomas S, Adler NM, Charytan DM, Gasmi B, et al. Megakaryocytes and platelet-fibrin thrombi characterize multi-organ thrombosis at autopsy in COVID-19: a case series. EClinicalMedicine. 2020;24:100434.

38. Díaz LA, Idalsoaga F, Cannistra M, Candia R, Cabrera D, Barrera F, Soza A, Graham R, Riquelme A, Arrese M, et al. High prevalence of hepatic steatosis and vascular thrombosis in COVID-19: a systematic review and metaanalysis of autopsy data. World J Gastroenterol. 2020;26(48):7693-706.

39. Gebrecherkos T, Gessesse Z, Kebede Y, Gebreegzabher A, Tasew G, Abdulkader M, Ebuy H, Desta A, Hailu A, Harris V, et al. Effect of co-infection with parasites on severity of COVID-19. medRxiv. 2021:2021.2002.2002.21250995

\section{Publisher's Note}

Springer Nature remains neutral with regard to jurisdictional claims in published maps and institutional affiliations. 